\title{
Anaemia is associated with reduced productivity of women workers even in less-physically-strenuous tasks
}

\author{
BY BARBARA D. SCHOLZ ${ }^{1}$, RAINER GROSS ${ }^{2 *}$, WERNER SCHULTINK ${ }^{2}$ \\ AND SOEMILAH SASTROAMIDJOJO ${ }^{1}$ \\ ${ }^{1}$ SEAMEO-TROPMED Regional Center for Community Nutrition, University of Indonesia, \\ Salemba Raya 6, Jakarta 10036, Indonesia \\ ${ }^{2}$ Deutsche Gesellschaft für Technische Zusammenarbeit (GTZ) GmbH, Eschborn, Germany
}

(Received 3 July 1995 - Revised 21 March 1996 - Accepted 1 May 1996)

\begin{abstract}
While many studies show reduced work output in heavy labour with poor nutritional status, data among less-physically-strenuous industrial occupations is scarce. In the present study the output of ninety-two women jute-factory workers over a 1 -month period was measured together with haemoglobin, BMI, arm muscle and fat area, physical work capacity (maximum $\mathrm{O}_{2}$ consumption; $\left.V_{\mathbf{O}_{2} \max }\right)$, as well as socio-economic, health and activity variables. A significant correlation was found between haemoglobin and work output, which remained significant $(P<0.005)$ after a multipleregression analysis with other potentially confounding factors. Anaemic workers and those with $V_{O_{2} \max }$ values less than $1.5 \mathrm{l} / \mathrm{min}$ were significantly less active at home than non-anaemic workers $(P<0.015)$. Anaemic women produced an average of $5.3 \%$ less in the factory and performed an average of $6.5 \mathrm{~h}$ less housework per week.
\end{abstract}

Anaemia: Physical work capacity: Nutritional status

Functional correlates of nutritional status can be a useful adjunct to anthropometric and laboratory indicators in the assessment of nutritional health and well-being. Functional correlates also provide a practical perspective to reference values and cut-off points, which would otherwise only be a reflection of a given population's norm, but not necessarily of its health and vitality.

In addition to morbidity and mortality data, functional consequences of malnutrition in adult populations have concentrated on assessment of physical-work capacity (as measured by the body's maximum $\mathrm{O}_{2}$ consumption; $V_{\mathrm{O}_{2} \max }$ ) or of actual work output, particularly in physically-strenuous agricultural occupations. These studies have shown significant positive correlations between weight, height, percentage body fat or lean body mass and both $V_{\mathrm{O}_{2} \max }$ and work output (Davies, 1973; Brooks et al. 1979; Spurr, 1984, 1987; Buzina et al. 1989; Diaz et al. 1991). Several studies have also shown a relationship between haemoglobin concentration and work output. A correlation was found between haemoglobin concentration and work output in Indonesian rubber tappers (Basta et al. 1979) and tea-plantation workers (Husaini et al. 1983). Another study on tea-estate workers in Sri Lanka (Gardner et al. 1977) and on road-construction workers in Kenya (Wolgemuth et al. 1982) supported a similar relationship between work output and Fe status. Anaemic tea-plantation workers in Sri Lanka who received a blood transfusion (Edgerton et al. 1979) or were Fe-treated (Edgerton et al. 1981) were found to be significantly more active, as well as achieving a higher work output.

\footnotetext{
*Present address: PO Box 3852, 10038 Jakarta, Indonesia.

$\dagger$ For reprints.
} 
Similar studies in more sedentary industrial occupations are relatively scarce, since generally it has been thought that outputs in heavy labour would more probably be affected by reduced endurance or fatigue accompanying low aerobic capacity or anaemia. However, a recent study in China (Li et al. 1994) showed that Fe supplementation of anaemic cotton mill workers increased their production efficiency, calculated as productivity:energy expenditure. Thus, supplementation enabled these women to do the same work at a lower energy cost.

The economic and social implications of reduced functional capacity due to anaemia are of great significance in both agricultural and industrial sectors. The present study attempts to determine whether work output in less-physically-strenuous occupations may also be affected by anaemia, and whether the relationships are similar to those found in occupations requiring a greater physical strength and endurance.

\section{METHODS}

\section{Subjects}

The subjects were 100 women, all of whom were loom operators from a jute mill on the outskirts of Jakarta, Indonesia. Of these, three were excluded due to pregnancy. To ensure more reliable work-output data, three additional subjects who had worked there less than 2 months (learning effects) and two subjects who had been absent for 2 weeks of the 4-week output data collection period were also excluded from the sample, leaving a final size of ninety-two subjects. All subjects were involved in the same task, so that the effort involved in obtaining a given work output could be judged to be more nearly similar. Each subject's rate of work was self-determined and independent of the output of other workers. There were no changes in management practices or work facilities during the period of measurement. Each woman was responsible for the smooth operation of two looms. This did not involve strenuous physical exercise, but required alertness and attentiveness. The amount of jute material produced was measured daily. Subjects worked 6 days per week for 8 hours per day in two shifts, starting at 06.00 hours and at 14.00 hours which were alternated weekly. All additional data besides work output was obtained from the women during the morning shift over a 2-week period.

\section{Data collection}

For collection of anthropometric and physical-fitness data and blood samples, the women were called in by the foreman at random from their workplace in groups of two to the factory clinic. While a sample of blood and measurements were taken from one, the other subject was questioned in a separate room by the factory nurse previously trained in the administration of a prepared questionnaire. The procedure was then reversed, making it impossible for each subject to hear the other's responses. Both subjects were asked to perform the step test, two on one bench, to aid adherence to the rhythm and to encourage completion of the test through peer competition. One subject began $30 \mathrm{~s}$ before the other, so that a $15 \mathrm{~s}$ pulse could be measured for each subject at the appropriate time.

\section{Nutrition-related variables}

Subjects were measured without shoes and with similar light clothing. Weight was measured to the nearest $0.1 \mathrm{~kg}$, using an electronic scale (SECA model 770; Seca, 
Hamburg, Germany). Height was obtained to the nearest $1 \mathrm{~mm}$ using a Stanley microtoise (CMS Weighing Equipment Ltd, London) with a movable bar and steel tape. BMI was calculated as weight $/$ height $^{2}\left(\mathrm{~kg} / \mathrm{m}^{2}\right)$. Arm circumference was measured to the nearest $1 \mathrm{~mm}$ at the midpoint of the right arm (halfway between the acromial and olecranon process of the ulna of the right arm) using a steel tape. Holtain skinfold calipers (Holtain Ltd, Crymych, Dyfed) were used to determine triceps skinfold thickness, taking the average of three measurements for each subject (Gibson, 1990). From these values, arm muscle and arm fat areas were calculated according to the method of Frisancho (1981), corresponding to the reserves of arm muscle protein and fat. The cyanomethaemoglobin method (International Nutritional Anaemia Consultative Group, 1985) was used to determine haemoglobin values (Merckotest; Merck, Darmstadt, Germany) from the average of two finger-prick blood samples of $0.02 \mathrm{ml}$ each. $V_{\mathrm{O}_{2} \max }$ was assessed from the pulse beat after the women had completed the step test of McArdle (1986). Using a $419 \mathrm{~mm}$ high bench, subjects stepped in a four-step cadence, up-up-down-down, at a rhythm set by a metronome at 88 beats $/ \mathrm{min}$. After $3 \mathrm{~min}$ the pulse rate was measured from 5 to $20 \mathrm{~s}$ of the recovery period, multiplied by 4 , and inserted into the following equation: $V_{\mathrm{O}_{2} \max }=65.81-(0.1847 \times$ recovery pulse in beats $/ \mathrm{min})$.

\section{Questionnaire}

A short questionnaire, requiring minimal disruption of factory flow, obtained information on major factors that could influence output or confound relationships with nutritional status. Subjects were asked for their age and formal education, which was determined as the last level completed, that is, primary (6 years), junior (9 years) or senior high school (12 years). The length of time the subject worked at the factory was determined from the starting date in the company records. Furthermore, the women were interviewed about the time they usually went to sleep and woke up to determine hours of sleep, as well as whether they walked to work or used another means of transportation. Subjects were also asked about habitual activity in terms of housework and sports. These were determined as hours per day spent cleaning, cooking, doing the wash and going to the market (housework variable), how many hours of sports per day (sports variable), as well as how many days per week each activity was pursued. Health status was assessed generally by asking whether the subjects had been sick in the past month, as well as determining whether they were taking any medication on the day they were questioned. Subjects were finally questioned about income and number of children. However, since most subjects did not wish to disclose the total family income, and work-output data would give more reliable estimates of their individual income than the subject's memory, estimates of income were excluded from the analysis.

\section{Collection of work output data}

The factory used two different types of looms. A time-motion study conducted earlier at the factory showed that for technical reasons, operators using one of the two types of looms required $5 \%$ more time to reach a standard output than those using the other type. Therefore, the output of each worker was expressed as the percentage of the overall average output of all workers operating the particular type of loom. Daily work output was obtained from the factory records for each worker for the twenty-four consecutive work days that the workers were present (excluding days absent) before the 2-week questionnaire 
period. Since only six workers had been absent in the past 4 weeks (for $1-3 \mathrm{~d}$ ), this corresponded to approximately the same 4-week period for all subjects.

\section{Data preparation and statistics}

Data were prepared using SPSS (Statistical Package for the Social Sciences, 1988). Normality was determined for all variables using the Kolmogorow-Smirnow test. Scatterplots of all variables $v$. work output were made to determine the presence of obvious non-linear relationships. Bartlett's test for homogeneity of variance was done for all ANOVA and by deviation of either normality or variance, the Kruskal-Wallace ANOVA for two or more groups was used instead of parametric methods. Plots of the residuals $v$. predicted values, and the histogram of the residuals showed linearity, equality of variance and normality for the regression analysis of haemoglobin $v$. work output.

\section{RESULTS}

\section{Characteristics of the population}

Table 1 shows the distribution of some of the socio-economic data of the subjects studied. All women had completed primary school, $21 \%$ finished junior high, and $15 \%$ the senior high school level. Most ( $82 \%$ ) of the workers had no children and shared their living quarters with other factory women; the rest (seventeen workers) had one to four children (fourteen had one to two children) and only three of all the women were the only source of income for their household. In the course of the interview, it became evident that the predominant activities of their lifestyle had been covered by the activity variables in the questionnaire.

Table 2 shows the means and standard deviations and ranges or frequencies of all study variables. All variables showed a normal distribution except for age, length of work, housework, sports and sleep. The data were consistent with internal reports about other factory workers in this area, so that the sample can be said to be fairly representative of this population.

Twenty-one subjects could be judged underweight with BMI below $18.5 \mathrm{~kg} / \mathrm{m}^{2}$. Of these, seven were below $17.5 \mathrm{~kg} / \mathrm{m}^{2}$. According to the Health and Nutrition Epidemiology Study I data from Frisancho (1981), 31.5 and $25 \%$ were below the 10th percentile by age for women for arm muscle area, and arm fat area, respectively. No subject had values

Table 1. Selected socio-economic variables of the Indonesian female factory workers studied (n 92)

\begin{tabular}{|c|c|c|}
\hline Variable & & $(\%)$ \\
\hline Age distribution: & $\begin{array}{l}16-18 \text { years } \\
19-29 \text { years } \\
\geq 30 \text { years }\end{array}$ & $\begin{array}{r}30 \\
62 \\
8\end{array}$ \\
\hline Formal education: & $\begin{array}{l}\text { Primary school } \\
\text { Junior high school } \\
\text { Senior high school }\end{array}$ & $\begin{array}{l}64 \\
21 \\
15\end{array}$ \\
\hline Children: & $\begin{array}{l}\text { No children } \\
\text { One to two children } \\
\text { Three to four children }\end{array}$ & $\begin{array}{r}82 \\
15 \\
3\end{array}$ \\
\hline
\end{tabular}


Table 2. Characteristics of study variables for Indonesian female factory workers* (n 92) (Mean values and standard deviations and ranges)

\begin{tabular}{|c|c|c|c|}
\hline Variable & Mean & SD & Range \\
\hline $\mathrm{Wt}(\mathrm{kg})$ & 44.9 & 5.5 & $35 \cdot 1-62 \cdot 7$ \\
\hline Height (m) & 1.49 & 0.06 & $1.48-1.62$ \\
\hline $\mathrm{BMI}\left(\mathrm{kg} / \mathrm{m}^{2}\right)$ & 20.0 & 1.9 & $16 \cdot 3-27 \cdot 1$ \\
\hline Arm muscle area $\left(\mathrm{mm}^{2}\right)$ & 2966 & 467 & $2024-4174$ \\
\hline Arm fat area $\left(\mathrm{mm}^{2}\right)$ & 1658 & 509 & $1572-3540$ \\
\hline Haemoglobin $(\mathrm{g} / \mathrm{l})$ & 117 & $13 \cdot 3$ & $80-159$ \\
\hline$V_{\mathrm{O}_{2} \max }: 1 / \min$ & 1.6 & 0.2 & $1.27-2 \cdot 18$ \\
\hline $\mathrm{ml} / \mathrm{kg}$ per min & $36 \cdot 3$ & 2.7 & $19.6-42.2$ \\
\hline Age (years) & 21.9 & 5.0 & $16-38$ \\
\hline Work length (months) & 29.4 & $34 \cdot 3$ & $2-130$ \\
\hline Housework (h/week) & 17.8 & 11.7 & $0-56$ \\
\hline Sports (h/week) & 0.6 & 1.5 & $0-7$ \\
\hline Sleep $(\mathrm{h} / \mathrm{d})$ & 7.5 & 0.8 & $6-9 \cdot 5$ \\
\hline Work output (\% average) & $100 \cdot 0$ & $12 \cdot 6$ & $70-136 \cdot 8$ \\
\hline
\end{tabular}

$V_{\mathrm{O}_{2} \max }$, maximum $\mathrm{O}_{2}$ consumption.

*For details of subjects, see p. 48 and Table 1.

Table 3. Mean work output (\% overall average output) and period of time spent on housework (h) at various values of haemoglobin for Indonesian female factory workers"

(Mean values and standard deviations)

\begin{tabular}{|c|c|c|c|c|c|}
\hline \multirow[b]{2}{*}{ Haemoglobin $(\mathrm{g} / \mathrm{l})$} & \multirow[b]{2}{*}{$n$} & \multicolumn{2}{|c|}{$\begin{array}{l}\text { Mean work output ( } \% \\
\text { overall average output) }\end{array}$} & \multicolumn{2}{|c|}{$\begin{array}{l}\text { Mean period of time } \\
\text { spent on housework (h) }\end{array}$} \\
\hline & & Mean & SD & Mean & SD \\
\hline$<100$ & 9 & $87.2 *$ & 9.8 & $14.9 \dagger$ & 7.9 \\
\hline $100-<110$ & 12 & 99.8 & $11 \cdot 4$ & 12.9 & 5.9 \\
\hline $110-<120$ & 25 & 99.9 & $14 \cdot 0$ & 14.8 & $10 \cdot 2$ \\
\hline $120-<130$ & 33 & $102 \cdot 3$ & $11 \cdot 6$ & $20 \cdot 3$ & $11 \cdot 3$ \\
\hline$\geq 130$ & 13 & 103.7 & $10 \cdot 8$ & $22 \cdot 3$ & $14 \cdot 5$ \\
\hline$<120$ & 46 & $97.4+$ & $13 \cdot 4$ & $14 \cdot 3 \S$ & $8 \cdot 7$ \\
\hline$\geq 120$ & 46 & $102.7^{\top}$ & $11 \cdot 2$ & $20 \cdot 8^{\circ}$ & $12 \cdot 9$ \\
\hline
\end{tabular}

Mean value was significantly different from those for the other four haemoglobin groups (ANOVA): ${ }^{*} P=0.018$. Mean value was significantly different from those for the other four haemoglobin groups (Kruskal-Wallace): $\dagger P=0.028$.

Mean value was significantly different from that of $\geq 120 \mathrm{~g} / \mathrm{l}$ group $(t$-test): $t P<0.015$.

Mean value was significantly different from that of $\geq 120 \mathrm{~g} / 1$ group (Kruskal-Wallace for two groups): $\$ P<0.015$.

|| For details of subjects and procedures, see pp. 48-50 and Tables 1 and 2.

above the 50th percentile. Table 3 shows that exactly $50 \%$ of the women were anaemic, having haemoglobin values below $120 \mathrm{~g} / 1$. Maximum aerobic capacity ( $\mathrm{ml} / \mathrm{kg}$ per min) was similarly distributed to that of the American population of McArdle (1986), with $55 \%$ of the population being at or below the 50th percentile. However, when expressed as $1 / \mathrm{min}, 81 \%$ of the $V_{\mathrm{O}_{2} \max }$ values were below $1.59 \mathrm{l} / \mathrm{min}$, which are values considered low for women (Wolgemuth et al. 1982), due to the lower weight and body size of these subjects. 


\section{Relationships between variables}

Table 3 shows the mean work outputs and hours of housework for several ranges of haemoglobin values. Anaemic subjects produced an average of $5.3 \%$ less $(95 \% \mathrm{CI}$ of $2.8-7.8 \%)$ and performed an average of $6.5 \mathrm{~h}$ less housework per week $(P<0.015)$.

According to the Spearman rank correlation matrix in Table 4, work output showed a significant positive linear relationship with haemoglobin and length of employment, and a negative correlation with hours of sports per week $(P<0.01)$. All anthropometric variables correlated strongly with each other, except that height correlated only with weight and arm muscle did not correlate with arm fat area. Hours of housework showed a positive linear relationship with haemoglobin as well as with length of employment $(P<0.01)$.

When subjects were grouped into approximately equal thirds according to their work outputs (Table 5), low and medium producers were both anaemic; only high producers had normal mean haemoglobin levels. Low producers engaged in $1 \mathrm{~h}$ more sports per week $(P<0.001)$, and had been employed for a significantly shorter period of time $(P<0.05)$. High producers tended to be sick less often than low or medium producers $(P<0 \cdot 10)$.

A significant relationship was also found between work output and educational level. Subjects with 9 years or less of education produced significantly more (101.3 (SD 12.7)\%) than those with 12 or more years $(93.2$ (SD 9.7)\%, $P<0.015$ ). No significant differences were seen between the mean work output and any other of the variables based on whether the subjects walked to work or not. Work output with the more efficient loom was $5.8 \%$ more than that with the other loom (5\% according to the factory's time-motion study); there were no significant differences in any of the other variables between loom types.

Twelve subjects felt unable to complete the step test. It is unclear whether these truly represent the portion of the sample with the lowest physical work capacity or whether motivation was simply low. Six of these subjects had BMI between 18.5 and $25 \mathrm{~kg} / \mathrm{m}^{2}$ but were feeling unwell and were taking medication at the time of the study. Of the remaining six, five had BMI below $18.5 \mathrm{~kg} / \mathrm{m}^{2}$ (mean $17.7 \mathrm{~kg} / \mathrm{m}^{2}$ ), and the sixth had a BMI of 27.1 $\mathrm{kg} / \mathrm{m}^{2}$. Subjects who failed were excluded only from the analysis involving $V_{\mathrm{O}_{2} \max }$.

No correlation was found between $V_{\mathrm{O}_{2} \max }$ and work output, nor was there any significant difference in the mean outputs at various levels of $V_{\mathrm{O}_{2} \max }$. Significant correlations were found between $V_{\mathrm{O}_{2} \max }$ and weight, height, BMI and arm fat area, but not with arm muscle area or haemoglobin. Although no linear relationship was found between activity at home and physical fitness (either as $\mathrm{ml} / \mathrm{kg}$ per $\mathrm{min}$ or $1 / \mathrm{min}$ ), there did appear to be a cut-off point among these subjects, below which activity at home decreased significantly. Women with values $<1.51 / \mathrm{min}$ did significantly less housework than those with higher $V_{\mathrm{O}_{2} \max }$ values $(5 \cdot 1 \mathrm{~h}$ less, $P<0.015)$.

In view of the many factors found to be related to work output (haemoglobin, work length, sports, education, illness), and the possibility of interactions between variables affecting the significance of relationships, the uniqueness of the relationship between the latter and haemoglobin was tested during a stepwise multiple regression. Work output was the dependent variable and the following were independent variables: weight, height, BMI, arm muscle area, arm fat area, haemoglobin, age, work length, housework, sports, sleep, as well as education and sickness in the past month (using dummy variables, where an education of 12 years and illness each took the value of 1).

Results showed that haemoglobin had the strongest unique significant relationship with work output of all the variables tested $(P<0.005, \mathrm{~B}=2.84)$, stronger than education and work experience, which followed in order of significance $(P<0.001$ and $P<0.05$ respectively). Haemoglobin accounted for $9.1 \%$ of the variability in output, and the three variables haemoglobin, education and work length accounted for nearly $20 \%$ of the variability. 


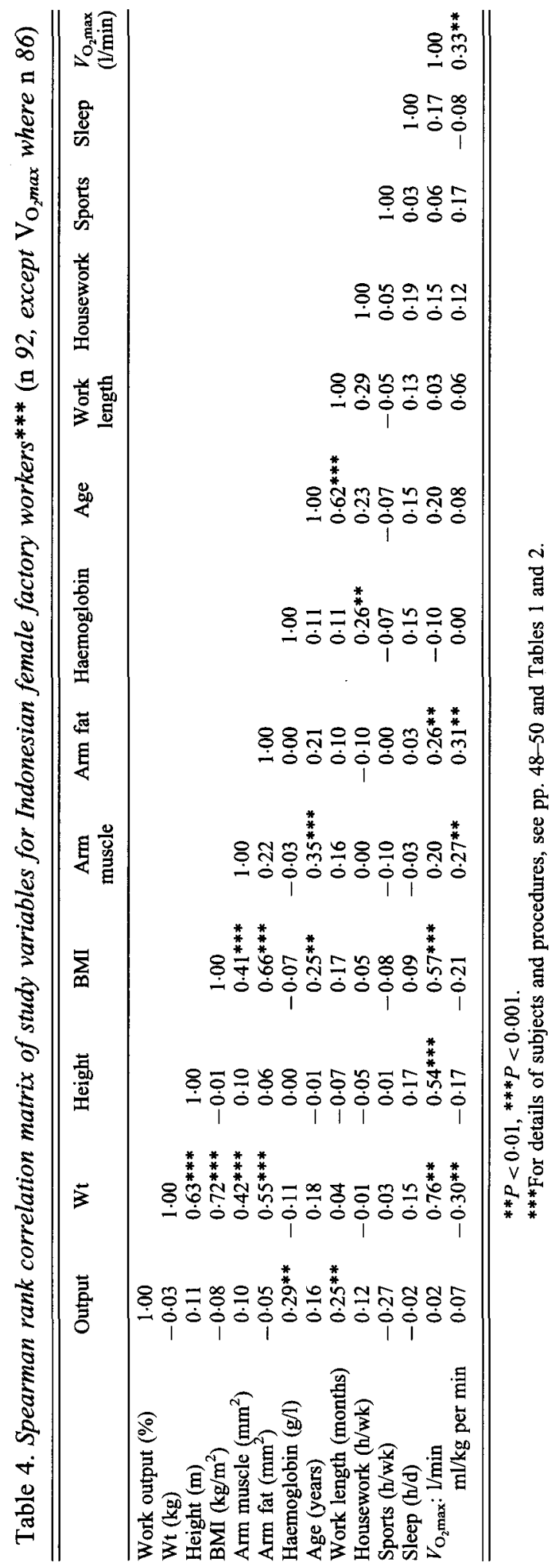




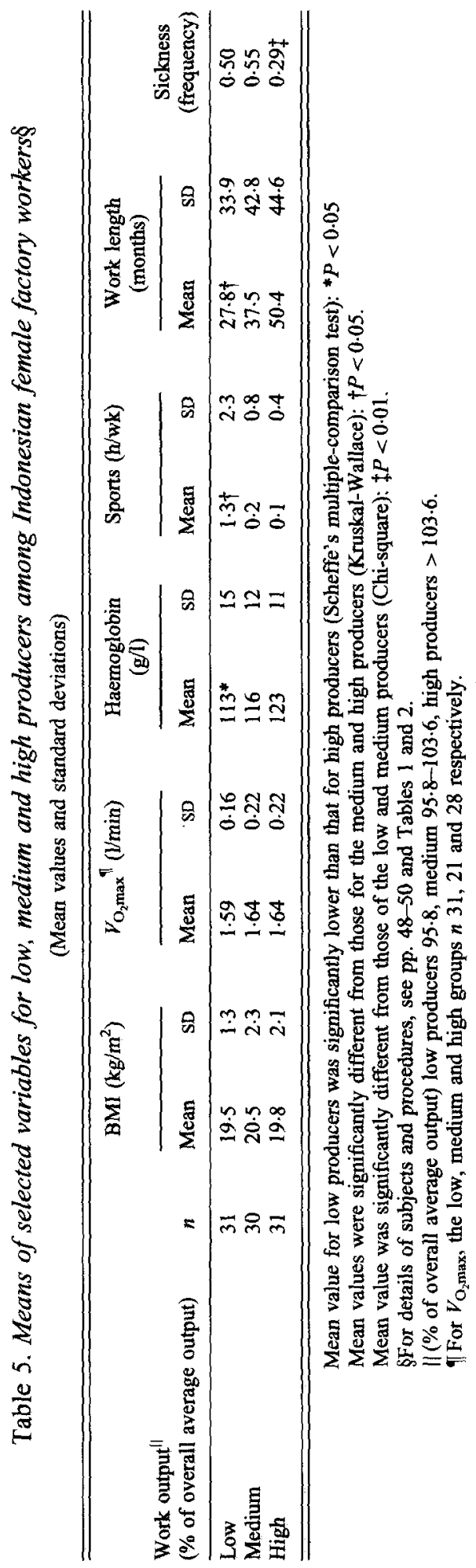




\section{DISCUSSION}

The results of the study show significant associations between functional deficits and anaemia in this factory task. This was seen primarily as a reduction in output among anaemic workers, and also as a reduction in activity outside the workplace among both anaemic workers and those with a low physical work capacity.

The relationship between anaemia and work output is of a similar magnitude to that found by Wolgemuth et al. (1982) among Kenyan construction labourers. Regression of haemoglobin $v$. work output (m earth moved $/ \mathrm{cm}^{2}$ ) showed a change of $3.6 \%$ in output for every $1 \mathrm{SD}$ change in haemoglobin, when output was expressed as the difference of each worker from the average daily output of all workers. In the present study, 1SD (13.3 g/l) change in haemoglobin was associated with a $3.7 \%$ change in work output.

Anaemia has generally been thought to affect output in terms of $\mathrm{O}_{2}$-carrying capacity of the muscles. Since the task in the present study was not physically strenuous and no association with physical work capacity was found, the nature of the relationship between haemoglobin and work output and home activity here remains to be elucidated. Although not physically strenuous, the factory task was very demanding in terms of attention or alertness. The quicker the potential stoppage of the looms was determined, the quicker it was set back into working order and the greater was the amount of jute material produced. Besides its effect on $\mathrm{O}_{2}$-carrying capacity during muscular work, there is a growing body of evidence, particularly among children, that Fe deficiency anaemia also interferes with perceptual and motor skills (Politt et al. 1983; Soemantri et al. 1985; Lozoff, 1989), particularly those involving attention. However, although most of the anaemia among women in Indonesia has been assumed to be related to Fe deficiency as indicated in its policy of large-scale Fe-tablet distribution, the cause of anaemia is not clear in the present study.

While anthropometric variables correlated strongly with one another in the present study, relationships with output, activity and haemoglobin were considerably weaker. Behavioural data such as work output and habitual activity, where human motivation and willpower play considerable roles, are subject to greater variability than correlations of purely physical data. For example, low motivation and job dissatisfaction may explain the negative relationship between education and output in the present study, since it is reasonable to assume that more-educated workers would consider factory work below their potential, unless socio-economic circumstances make it unavoidable. Furthermore, although no obvious non-linear relationships were seen in scatterplots, non-linear regression coefficients may fit the data more exactly. For example, the difference in mean output at haemoglobin levels of $<100 \mathrm{~g} / 1$ appear greater than changes at other levels (Table 3).

The significant positive correlations found between height, weight, total body haemoglobin and $V_{\mathrm{O}_{2} \max }$ found in the present study support other findings (Spurr, 1984, 1987). The mean $V_{\mathrm{O}_{2} \max }(1 / \mathrm{min})$ of the factory women is low compared with non-athletic Caucasian female populations with a mean of 2-2.11/min (Astrand, 1960) or with an Asian population of Japanese students $(1.8 \mathrm{l} / \mathrm{min})$ (Astrand \& Rohl, 1986). However, when expressed as $\mathrm{ml} / \mathrm{kg}$ per $\mathrm{min}$, the women showed a distribution very similar to that of American students (McArdle, 1986), showing that the difference was due mainly to differences in weight or body size. This is in agreement with other findings showing that $V_{\mathrm{O}_{2} \text { max }}$ per $\mathrm{kg}$ is similar between ethnic groups of similar habitual activity (Wyndham et al. $1963)$. No relationship was found between the capacity for physical work $\left(V_{\mathrm{O}_{2} \max }\right)$ and output or between the latter and any anthropometric variable in this less-physicallystrenuous task. 
On the basis of the present study it can be concluded that there is a unique association between haemoglobin and work output, independent of the fourteen other factors included in the regressions analysis. This result provides a strong indication for intervention studies determining effects of Fe supplementation on work output not only of heavy work but also of sedentary industrial occupations, assuming such a relationship is reversible as well as causal. Since it was not the purpose of the present study to determine relationships between habitual physical activity and nutritional indicators; the variable housework was included as a rather crude indicator (in comparison with mechanical activity monitors) of a potentially confounding factor related to factory work output, namely tiredness due to excessive activities at home. This variable nevertheless turned out to be the most persistently significant in the present study, and was probably an adequate activity indicator due to the relatively few and routine extra-work activities the subjects engaged in. The results point out the importance of considering the probable social, as well as economic, consequences of anaemia through its association with the reduction of socially-desirable, extra-work activities. These may include only household tasks as measured in the present study, or may include reductions in the ability to carry out more socially valuable tasks such as child care, or potentially income-generating, educational, self-improvement activities.

This study was financially supported by the German Federal Ministry of Economic Cooperation and Development through the Deutsche Gesellschaft für Technische Zusammenarbeit (GTZ) GmbH. The authors wish to thank Noel Solomons and D'Ann Finley for their helpful comments on the manuscript.

\section{REFERENCES}

Astrand, I. (1960). Aerobic work capacity in men and women with special reference to age. Acta Physiologica Scandinavica 49, Suppl., 169.

Astrand, P. O. \& Rohl, K. (1986). Textbook on Work Physiology. New York: McGraw Hill Book Co.

Basta, S. S., Soekirman, Karyadi, D. \& Scrimshaw, N. S. (1979). Iron deficiency and productivity of adult males in Indonesia. American Journal of Clinical Nutrition 32, 916-925.

Brooks, R. M., Latham, M. C. \& Crompton, D. W. T. (1979). The relationship of nutrition and health to worker productivity in Kenya. African Medical Journal 56, 413-421.

Buzina, R., Bates, C. J. \& van der Beek, J. (1989). Workshop on the functional significance of mild-to-moderate malnutrition. American Journal of Clinical Nutrition 50, 172-176.

Davies, C. T. M. (1973). Relationship of maximum aerobic power output to productivity and absenteeism of East African sugar cane workers. British Journal of Industrial Medicine 30, 146-154.

Diaz, E., Goldberg, G. R., Taylor, M., Savage, J. M., Sellen, D., Coward, W. A. \& Prentice, A. M. (1991). Effects of dietary supplementation of work performance in Gambian laborers. American Journal of Clinical Nutrition 53, 803-811.

Edgerton, V. R., Gardner, G. W., Ohira, Y., Gunawardena, K. A. \& Senewiratne, B. (1979). Iron deficiency anemia and its effect on worker productivity. British Medical Journal 2, 1546-1549.

Edgerton, V. R., Ohira, Y., Hettiarachchi, T., Senewiratne, B., Gardner, G. W. \& Barnard, R. J. (1981). Elevation of hemoglobin and work performance in iron-deficient subjects. Journal of Nutritional Science and Vitaminology 27, 77-86.

Frisancho, A. R. (1981). New norms of upper limb fat and muscle area for assessment of nutritional status. American Journal of Clinical Nutrition 34, 1540-1545.

Gardner, G. W., Edgerton, V. R., Senewiratne, B., Barnard, R. J. \& Ohira, Y. (1977). Physical work capacity and metabolic stress in subjects with iron deficiency anaemia. American Journal of Clinical Nutrition 30, 910-917.

Gibson, R. S. (1990). Principles of Nutritional Assessment. New York: Oxford University Press.

Husaini, M. A., Karyadi, D. \& Gunadi, H. (1983). Evaluation of nutritional anaemia intervention among anaemic female workers on a tea plantation. In Iron deficiency and Work Performance, pp. 73-78 [L. Halberg and N. Scrimshaw, editors] Washington DC: The Nutrition Foundation.

International Nutritional Anemia Consultative Group (1985) Measurements of Iron Status. Washington DC: International Nutritional Anemia Consultative Group. 
Li, R., Chen, X., Yan, H., Deurenberg, P., Garby, L. \& Hautvast, G. A. J. (1994). Functional consequences of iron supplementation in iron-deficient female cotton mill workers in Beijing, China. American Journal of Clinical Nutrition 59, 908-913.

Lozoff, B. (1989). Iron and learning potential in childhood. Bulletin of the New York Academy of Medicine 65, $1050-1066$.

McArdle, W. D. (1986). Individual differences and measurement of energy capacities. In Textbook of Exercise Physiology, pp. 167-187 [W. D. McArdle, F. J. Katch and V. L. Katch, editors]. Philadelphia: Lea and Febiger.

Politt, E., Leibel, R. L. \& Greenfield, D. B. (1983). Iron deficiency and cognitive test performance. Nutrition and Behaviour 1, 137-143.

Spurr, G. B. (1984). Physical activity, nutritional status and physical work capacity in relation to agricultural productivity. In Energy Intake and Activity, pp. 207-261. New York: Alan Liss Inc.

Spurr, G. B. (1987). Effects of chronic energy deficiency on stature, work capacity and productivity, In Chronic Energy Deficiency: Consequences and Related Issues, pp. 95-134 [B. Schürch and N. S. Scrimshaw, editors]. Lausanne: International Dietary Energy Consultative Group.

Soemantri, A. C., Politt, E. \& Kim, I. (1985). Iron deficiency anemia and education achievement. American Journal of Clinical Nutrition 42, 1221-1228.

Statistical Package for the Social Sciences (1988). SPSSx User's Guide, Chicago, IL: SPSS Inc.

Wolgemuth, J. C., Latham, M. C., Chesher, A., Hall, A. \& Crompton, D. W. T. (1982). Worker productivity and the nutritional status of Kenyan road construction laborers. American Journal of Clinical Nutrition 36, 68-78.

Wyndham, C. H., Strydom, N. B., Morrison, J. F., Peter, J., Williams, C. G., Bredel, G. A. G. \& Joffe, A. (1963). Difference between ethnic groups in physical working capacity. Journal of Applied Physiology 18, $361-368$. 


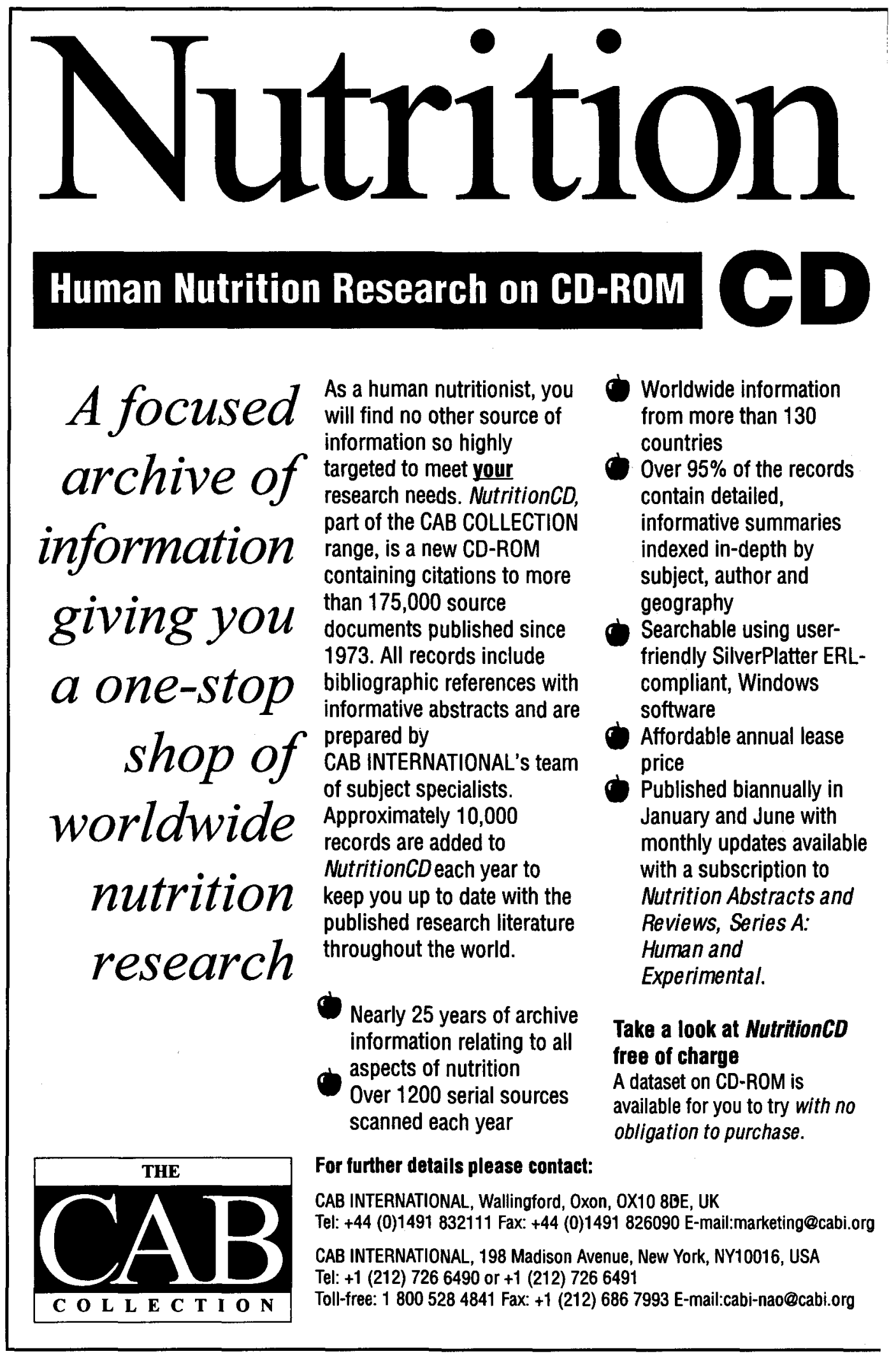

